\title{
O MÉTODO CIENTÍFICO EM CIÊNCIAS SOCIAIS: DOS DOCUMENTOS, QUESTIONÁRIOS E ENTREVISTAS À ANÁLISE DE ENUNCIADOS
}

\author{
Oscar José Rover*
}

\begin{abstract}
Resumo
O artigo propõe um conjunto de reflexões para tratar do método em ciências sociais. As entrevistas e a análise de conteúdo são os principais instrumentos metodológicos analisados. Ele explicita um conjunto de orientações consideradas necessárias ao fazer metodológico das ciências sociais, visando escapar de armadilhas e artimanhas dos jogos de palavras. Como todos os processos de leitura, transcrição e análise de textos envolvem a comunicação entre universos cognitivos diferentes, ocorre nestes uma transformação do conteúdo. Conclui-se que há necessidade de o cientista assumir e explicitar que reapresenta textos e contextos sob a construção literária por ele definida como apropriada.
\end{abstract}

Palavras-chave: Ciências Sociais. Instrumentos Metodológicos. Entrevistas. Análise de Conteúdo

*Mestre em Sociologia Política (UFSC). Doutor em Desenvolvimento Rural (UFRGS), professor da Universidade Federal de Santa Catarina. E-mail: oscar.rover@ufsc.br 


\section{Introdução}

Neste artigo se apresentará uma discussão sobre o ato de fazer ciências sociais e de torná-las públicas através de materiais escritos, como uma forma de transformar ideias coletadas a partir de entrevistas, discursos, documentos. Essa transformação é indicada como se processando ao longo de todo o processo de pesquisa, mas particularmente na escolha dos instrumentos de pesquisa, na coleta de dados e informações, e na interpretação posterior do material coletado. Assim, o cientista faz a construção de sua própria percepção do real, apresentando-o sob outra construção literária, diferente, por exemplo, daquela dada por pessoas que tenham sido entrevistadas.

Procurarei aprofundar o debate acerca do uso de dois procedimentos metodológicos utilizados na pesquisa em ciências sociais, quais sejam: a entrevista e a análise de conteúdo. No caso das entrevistas, transitarei por aquelas com questionários semiestruturados e as com questionários não estruturados. No caso da análise de conteúdo, terá foco a análise de documentos, textos e de entrevistas. Apresentarei, por fim, alguns limites das abordagens clássicas de análise de conteúdo.

\section{Qual ciência, qual método?}

Proponho uma discussão que se posiciona contra os extremos do empirismo, de um lado, e do teoricismo, de outro. Neste sentido, a noção de vigilância epistemológica proposta por Bourdieu (1999) é considerada como central, devendo abranger todos os aspectos da pesquisa. Assim, evidenciar os pressupostos teóricos que estão colocados para o pesquisador no momento em que opta por tema e por método de pesquisa é central, assim como o é, revelar as possíveis fontes de distorção que podem se gerar, seja na construção do objeto, na definição ou aplicação dos métodos de pesquisa, ou na análise e processamento das informações coletadas.

Para Thiollent (1980, p. 25), o questionamento sociológico é um sistema de perguntas e respostas que circulam, onde tal "circulação é interativa até o ponto de se chegar à melhor compreensão recíproca possível”. É no controle da articulação entre os questionamentos e a problemática teórica que se constroem garantias contra o empirismo, e é desta forma também 
que se pode afastar-se de um teoricismo exacerbado. Citando Habermas, Thiollent (1980,p.24), propõe "o questionamento como comunicação" e o encontro entre pesquisador e pesquisado "no terreno intersubjetivo de uma possível compreensão", isto devendo ser feito com base em algum controle metodológico. Desta forma, o método aparece como central no fazer científico e determinante dos resultados do processo comunicativo, especialmente quando se considera que em um processo de pesquisa ocorre não apenas a comunicação entre diferentes indivíduos, mas normalmente entre diferentes mundos sociais (BOURDIEU, 1999).

Parto do pressuposto de que não existe neutralidade científica na pesquisa sociológica. Seja no que se refere à escolha do objeto/sujeito a ser pesquisado, seja no processo de pesquisa, por mais que o ato de fazer ciência não deva abrir mão de "buscar uma neutralidade", a neutralidade é um pressuposto falso ou inexistente (THIOLLENT,1980, p.28).Para esse autor, "qualquer procedimento de investigação envolve pressupostos teóricos e práticos variáveis segundo os interesses sociopolíticos que estão em jogo no ato de conhecer". Neste sentido, mesmo quando estou escrevendo um projeto de pesquisa e tanto mais quando estou escrevendo um relatório, ou um artigo proveniente destes, estou expressando a construção de um "raciocínio argumentativo" (HABERMAS, 1989) com o leitor.

A pragmática da escrita visa "Orientar o leitor para os traços sociologicamente pertinentes que a percepção desarmada ou distraída deixaria escapar" (BOURDIEU, 1999, p. 709). Ao apresentar uma pesquisa para os objeto-sujeitos dela, ou para qualquer outra pessoa, estou dialogando o que meus métodos de pesquisa me permitiram alcançar com as informações que imagino serem pertinentes apresentar ao público. Mas, anterior a isso, a própria seleção de métodos, os elementos apresentados pela realidade e definidos pelo pesquisador como pertinentes a serem mais explorados, aprofundados, analisados, são, de alguma maneira, "uma interpretação" da realidade social em estudo. Para Thiollent (1980, p. 22), o trabalho de pesquisa social já vem orientado por uma teoria, que é entendida como "problemáticas, como fontes de conceitos ou de hipóteses necessárias à concepção de projetos de pesquisa relativos a determinados assuntos cuja relevância social e científica precisa ser discutida".

Para Bourdieu (1999, p. 711), "toda leitura já está, senão obrigada, pelo menos orientada por esquemas interpretativos",
1 Considere-se aqui o ponto de vista de Bourdieu de que a fala, $o$ ato performático, a escrita e mesmo a leitura, já são previamente orientados pela filiação instituída ao referente. "O uso da linguagem, ou melhor, tanto a maneira como a matéria do discurso, depende da posição social do locutor que, por sua vez, comanda o acesso que se lhe abre à língua da instituição, à palavra oficial, ortodoxa, legítima" (BOURDIEU, 1998, p. 87). 
ou seja, quando estamos num processo de leitura de uma realidade estamos transcrevendo-a, redefinindo-a, assim, interpelando nosso ponto de vista sobre a mesma. "Transcrever é necessariamente escrever, no sentido de reescrever" (BORDIEU, 1999, p. 710). O mesmo autor afirma que "a transcrição muito literal já é uma verdadeira tradução ou até uma interpretação" (BORDIEU, 1999, p. 709), falando da entrevista. Para Thiollent (1980, p.38) a pesquisa sociológica sempre é construída em função de um método teórico explicitamente formulado, o que, por sua vez, já impõe uma orientação ao processo de pesquisa.

Fica então a questão: o que se faz pertinente, ou o que deve ser próprio do fazer científico? O que diferenciaria a ciência social de outras práticas discursivas? Seria o método? Mas qual método, no arranjo de diversidades metodológicas existentes? $\mathrm{O}$ compromisso do pesquisador em explicitar a realidade "tal qual ela é" é apresentado por muitos como central do fazer científico em ciências sociais. Esta forma de ver a ciência é vista aqui como uma das expressões do positivismo tão presente ainda nas ciências sociais da atualidade, pois a realidade só aparecerá "tal qual ela é" do ponto de vista de quem a desenhou em seu discurso, especialmente se partilhamos do mesmo pensar que Berger e Luckmann (apud BAUER; GASKELL 2003, p. 20), que "o mundo, como o conhecemos e experienciamos, isto é, o mundo representado e não o mundo em si mesmo, é constituído através de processos de comunicação". Para eles, a pesquisa social se apoia em dados sociais que são construídos nos processos de comunicação, e é resultado destes. Essa comunicação pode ser mais formal (textos, imagens etc.) ou mais informal (falada etc.). Parto do pressuposto de que quando estudamos uma dada realidade, buscando aproximar-nos ao máximo da expressão da realidade na forma que os sujeitos da realidade em estudo a concebem, fazse necessário cruzar o máximo de instrumentos metodológicos que apreendam mecanismos de comunicação formal e informal, e abstraiam dos atores sociais suas impressões e expressões da realidade.

Bourdieu (1999,p.712), quando trata da relação pesquisadorpesquisado, falando das entrevistas, propõe restituir ao pesquisado sua razão de ser e sua necessidade, buscando tornar evidente sua visão do mundo. Aproximando-se deste entendimento, Michelat (1980, p.193), apresentando as vantagens das entrevistas não diretivas, afirma que há informações que poderiam ser censuradas 
na aplicação de questionários ou outro tipo de entrevista, que ganham liberdade para aparecer na entrevista não diretiva. E complementa dizendo que elas permitem o acesso a informações que não podem ser atingidas diretamente, "permitindo a emergência deste conteúdo sócio-afetivo profundo" (BORDIEU, p. 194).

Isto justamente para não tomar a visão de mundo do pesquisador como se fosse ela a expressão do social pesquisado, afinal, "a informação obtida em situação unilateral é mais significativa das categorias e das representações contidas no dispositivo de captação do que da representação do universo investigado" (THIOLLENT, 1980, p. 24). Não basta, pois, apresentar o mundo tal como ele é, mas os motivos e necessidades que levaram os diferentes atores sociais a construir o mundo social em que vivem.

Bauer e Gaskell (2003, p. 32), se referindo à pesquisa qualitativa indicam que é necessário “compreender as interpretações que os atores sociais possuem do mundo, pois são estas que motivam o comportamento que cria o próprio mundo social". Considero importante compreender que no processo da pesquisa não aparecem apenas os dados frios do mundo "tal qual ele é”, nem apenas as necessidades, motivos e interpretações dos diferentes atores sociais, mas também as necessidades, motivos e interpretações dos pesquisadores, no contexto das diferentes leituras de mundo de cada um destes, sejam pesquisadores e/ou pesquisados.

Bauer e Gaskell (2003, p. 33) citam Habermas para afirmar que é através de um "processo auto-reflexivo" ou racional que se podem identificar estruturas condicionadoras de poder que produzem uma "comunicação sistematicamente distorcida e de uma repressão sutilmente legitimada", e também que "a aplicação da razão é fundamentalmente um empreendimento crítico". A racionalidade crítica dos pesquisadores (da ciência) é mais importante para "a possibilidade de uma ação emancipatória que a escolha da técnica empregada” (BAUER; GASKELL, p. 35).

\section{Sobre questionários e entrevistas}

Por mais que concorde que a racionalidade crítica do pesquisador é central para a produção de conhecimento emancipatório, considero importante não perder de vista 
que a escolha de métodos adequados tanto pode produzir um conhecimento legítimo para a construção de processos emancipatórios, quanto, em outro extremo, para perdurar dinâmicas de opressão. Bauer e Gaskell (2003) ponderam quanto à necessidade de ter consciência das vantagens e desvantagens dos diferentes métodos, adequando seu uso para diferentes situações sociais, diferentes tipos de informações e diferentes problemas sociais.

Indico que o uso e cruzamento de variados métodos e técnicas de pesquisa possibilitam maior compreensão do real, pautada na evidenciação de estruturas, práticas e pensares facilmente disponíveis, ou mais velados, da organização social em estudo. Entretanto, darei foco aos questionários e entrevistas como procedimentos metodológicos salutares. Para Thiollent (1980, p. 21),

[...] o uso de questionários e entrevistas não é sinônimo de empiricismo quando estas técnicas, consideradas como meios de captação de informação, a ser criticada, e não como fins em si, são submetidas ao controle metodológico e subordinadas a uma verdadeira preocupação de teoria sociológica.

As entrevistas são consideradas técnicas de observação direta, na medida em suscitam uma reação por parte dos pesquisados, que têm, portanto, uma ação ativa. Desta maneira, elas e seus questionários são vistos em contraposição à análise de documentos e de imagens, que é considerada uma técnica de observação indireta. Questionários e entrevistas, como técnicas, são vistos como "dispositivos de obtenção de informações cujas qualidades, limitações e distorções devem ser metodologicamente controladas" (THIOLLENT, 1980, p. 22). Numa linha semelhante, Bauer e Gaskell (2003) chamam de dados formais aqueles prontamente disponíveis em documentos e textos, e informais aqueles construídos via observação direta, no contato com o público pesquisado.

Tratando especificamente dos dados formais ou observação indireta, Thiollent (1980, p. 32) afirma que, nos questionários mais fechados, as perguntas correspondem a uma "tradução das hipóteses da pesquisa sob forma interrogativa”. Eles caracterizamse pela extensividade (grande número de pessoas e fechamento destas). Já no outro extremo, as entrevistas não estruturadas caracterizam-se pela intensividade (pequeno número de pessoas 
e grande abertura das perguntas para maior profundidade - esta última buscando o ponto de vista mais afetivo do que racional do pesquisado). Aqui, vale comentar que para Michelat (1980, p.196), a entrevista não diretiva (chamada, por Thiollent, de não estruturada) permite "reconstituir os modelos culturais de nossa sociedade", quando realizadas com indivíduos representativos de um grupo social. Cada entrevista e cada indivíduo, neste caso, representa uma amostra do universo sobre o qual se quer falar.

Quando o tema da pesquisa é muito aberto, o questionário é substituído por roteiro de entrevista, ou quando mais, por uma entrevista não diretiva orientada por uma instrução ou tema chave (THIOLLENT, 1980, p. 33). Para Bourdieu (1999, p. 704), a entrevista pode ser considerada como uma "forma de exercício espiritual, visando obter, pelo esquecimento de si, uma verdadeira conversão do olhar que lançamos sobre os outros nas circunstâncias comuns da vida”. Já para Bauer e Gaskell (2003, p. 21), "pode acontecer que o foco central da pesquisa social seja desvelar a ordem oculta do mundo informal da vida cotidiana”. Neste tipo de situação, recomendam que "devemos reconhecer falsas falas que dizem mais sobre o pesquisador e sobre o processo de pesquisa, do que sobre o tema pesquisado". Para Michelat (1980, p. 2034), "é necessário ir do conteúdo manifesto ao conteúdo latente, especialmente se queremos reconstituir o raciocínio subjacente (inconsciente, afetivo) que preside a emergência dos temas manifestos”. Propõe analisar a retórica espontânea dos discursos espontâneos, identificando lapsos nesta retórica e relacionandoos com o conjunto da análise (MICHELAT, 1980, p. 211). O mesmo autor cita Laplanche e Pontalis, quando se refere à análise de entrevistas não diretivas, para acrescentar que "se cada elemento manifesto é determinado por várias significações latentes, cada uma destas, inversamente, pode ser encontrada em vários elementos" (MICHELAT, p. 206).

Para Bardin (1977, p. 171), o discurso é visto como atualização parcial de processos e como "estruturação e conjunto de transformações provocadas pela passagem pelo 'fluxo' da linguagem e pelo 'outro"'.

Torna-se importante, aqui, fazer uma diferenciação mais clara entre entrevistas e questionários. Thiollent (1980) apresenta cinco tipos de entrevistas, quais sejam:

a) dirigida ou padronizada: com questionários estruturados;

b) semiestruturada: com pequeno número de perguntas; 
c) centrada: orientando a entrevista apenas pela hipótese e certos temas da pesquisa;

d) não diretiva ou aprofundada: a partir de tema geral sem estruturação de problema pelo pesquisador;

e) clínica: conduzida de maneira não diretiva, com preocupação psicossociológica.

À exceção das entrevistas não estruturadas ou clínicas, nas demais situações sempre se usa algum tipo de questionário, mesmo que pouco estruturado. Como a opção deste trabalho não são os questionários dirigidos e padronizados, acrescentarei comentários, a título de aprofundamento, quanto às entrevistas.

Uma das dimensões que marca as entrevistas é relativa à natureza das informações que se busca obter, a qual pode ser de caráter factual, relativa à percepção do pesquisado, à sua opinião, ligada a elementos atitudinais do interlocutor ou, ainda, apenas de caráter reativo. Selltiz (1974 apud THIOLLENT, 1980), propõe uma classificação das entrevistas quanto à direção dada aos conteúdos das perguntas, indicando que eles podem buscar: verificação de fatos; verificação de crenças quanto aos fatos; verificação de sentimentos; descoberta de padrões de ação; estudo de comportamento presente e passado; razões conscientes de crenças, sentimentos, orientações ou comportamentos, acrescentando que "em geral, os questionários contém uma combinação de diversos tipos de conteúdos de perguntas" (SELLTIZ, 1974, p. 36 apud THIOLLENT, 1980).

Dependendo do assunto a ser tratado, pode-se ter uma orientação quanto à maior ou menor abertura do questionário a ser utilizado numa entrevista, ou até da não utilização de um questionário. No caso de trabalhar-se com um assunto aberto, ele pode ser substituído por um roteiro de entrevista, ou quando mais, por uma entrevista não diretiva orientada por uma instrução ou tema chave.

A informação conseguida por questionário, a mais facilmente acessível, é também a mais superficial, estereotipada e racionalizada. "Se uma entrevista não-diretiva (sic) é utilizada de preferência a uma entrevista dirigida a partir de um questionário é porque se considera que a informação fornecida por perguntas diretas solicita apenas a parte da informação imediatamente acessível ao entrevistado, isto é, a informação mais superficial, mais estereotipada, mais sensível às pressões da desejabilidade social" (MICHELAT, 1980, p. 202). 
Por sua vez, as entrevistas não diretivas normalmente geram problemas na relação entre perguntas e respostas, internamente ao processo de entrevistar, quais sejam: os problemas colocados pelos entrevistados podem ser completamente diferentes dos que o pesquisador imaginaria ou proporia; o analista, portanto, no momento da análise, impõe respostas ao entrevistado que podem não corresponder ao que ele teria escolhido, ou ao que teria um significado para ele (MICHELAT, 1980, p. 193).

Em qualquer pesquisa se está preocupado com a validação das informações obtidas e que comporão "nossa expressão científica do real". Especialmente quando se trata de entrevistas com questões mais abertas, a validação tem um papel central, para saber se a resposta corresponde à realidade estruturada ou pensada pelos entrevistados. Isto exige recorrer a procedimentos e perguntas diferentes para controlar os resultados. A entrevista não diretiva, por exemplo, por sua atitude centrada sobre a pessoa entrevistada, apresenta o risco de perder o foco da pesquisa em si, quando é a condição e o caminho incondicionalmente dado pelo entrevistado que conta (BARDIN, 1977, p. 172). Ela é recomendada para a pesquisa social, porém é adequado não utilizá-la como única técnica de pesquisa, tendo um uso exclusivo mais adequado em situações de psicologia social ou antropologia. Para Michelat (1980, p. 197), "a análise [fazendo referência ao procedimento de análise de entrevistas não diretivas] baseia-se mais no que é sentido do que no que é conhecido". Este é um caso notório em que a utilização de um número maior de métodos e procedimentos de pesquisa só trará resultados positivos.

Por mais que seja o caminho dado pelo entrevistado que conta, faz-se importante considerar que mesmo a entrevista não diretiva possui elementos de não diretividade, como demonstra Bardin (1977, p.173), quais sejam: "as instruções temáticas postas para centrar a entrevista no assunto que interessa o entrevistador e a presença deste como interlocutor". Como há instruções temáticas que centram diferentes entrevistas que podem ser feitas sobre um mesmo tema e atores sociais que transitam num mesmo espaço social, pode-se dizer que é possível trabalhar-se com uma dimensão de comparação entre as respostas dos diferentes atores, justamente em função de uma condição de standardização inicial dada pela(s) temática(s) centralizadora. Michelat (1980, p. 198) cita Sapir para apontar a necessidade de admitir a existência de determinadas constantes no interior de relações interpessoais 
2 Para Ghiglione e Matalon (1997, p.58), quando não se tem como objetivo na construção dos "inquéritos" (podemos entender aqui como entrevistas) a estimativa de grandezas, a representatividade de uma amostra passa a ser uma condição menos necessária para a validade dos resultados. Para estudos mais em profundidade talvez seja mais importante se perguntar quais as particularidades locais que podem falsear os resultados. de indivíduos habituados a viver em comum. Daí deduz que do comum em certo número de indivíduos, extrapola-se na análise para modelos culturais.

Assim, mesmo no caso das entrevistas não diretivas podese trabalhar com um universo relativamente amplo de corpus, passíveis de cruzamento e comparação, além de uma análise mais totalizante. Um conjunto de entrevistas, ou mesmo uma só, permite formar um esquema, mesmo que provisório, de entendimento de tal conjunto. Isso só se faz possível após uma necessária “impregnação [noção extraída de Lévi-Strauss]" que o analista venha a ter de seu conteúdo (MICHELAT, 1980). O que difere esse tipo de entrevista dos outros talvez seja o fato de cada entrevista ser original e singular nas mesmas palavras de Bardin (1977), de poder explorar mais intensivamente os temas escolhidos pelo pesquisador, o que obriga, por isto, a limitar do número de entrevistas que se poderá realizar. Isso porque, para interpretação de entrevistas não diretivas, é necessário que se proceda a leituras e releituras das transcrições das entrevistas até chegar a uma espécie de impregnação. Para Michelat (1980, p. 209), "é necessário parar quando se considera que o estado atual do modelo obtido [de interpretação] atinge certa estabilidade”. A noção de impregnação, agregada à ideia de estabilidade, aproxima-se à ideia de saturação do corpus de pesquisa, à medida que o pesquisador percebe que começam a se tornar repetitivas novas entrevistas e materiais com dados e conteúdos. Cada unidade de entrevista aqui é entendida como um corpus. Importante considerar que há uma concordância entre os autores que trabalham com entrevistas em profundidade de que não são necessárias, normalmente, mais que 40 entrevistas para garantir um bom universo que possibilite gerar extrapolações interpretativas para um conjunto social em estudo ${ }^{2}$.

A entrevista é uma relação de troca e "nesta relação de troca, cada um engana um pouco ao outro ao se enganar a si próprio" (BOURDIEU, 1999, p. 703). "É necessário um exame dos mecanismos sociais e cognitivos operantes nos instrumentos de investigação (questionários e entrevistas), tendo em vista a localização e o controle das interferências ideológicas que se manifestam ao nível da obtenção dos dados" (THIOLLENT, 1980 , p. 30). Fazendo relação com esta questão da obtenção das informações antes da análise, Michelat (1980, p. 201) apresenta um conjunto de críticas à análise de conteúdo, sendo uma das mais consistentes, em minha opinião, "o isolamento dos temas de seu 
contexto relacional [, que] parece-nos fazer perder a compreensão das ligações necessárias para atingir o conteúdo latente". Importante observar que essa tomada de posição de Michelat diz respeito, segundo ele, à postura da maior parte dos usos dados à análise de conteúdo. Estes usos, neste sentido, divergem também do ponto de vista de Bardin, conforme apresentado neste trabalho. Enfatizo a importância de trabalhar cuidados metodológicos para não perder elementos-chave do conjunto social que se deseja pesquisar, pois partilho do posicionamento de Bauer e Gaskell (2003, p. 29), para quem "os métodos e os procedimentos são o meio científico de prestação de contas pública com respeito à evidência”.

\section{A análise dos conteúdos das entrevistas e questionários}

A análise de conteúdo é entendida aqui como o procedimento de interpretação de conteúdos discursivos, sejam eles documentais ou a partir de entrevistas. Ela pode ser considerada como "um conjunto de técnicas de análise das comunicações, que utiliza procedimentos sistemáticos e objetivos de descrição do conteúdo das mensagens" (BARDIN, 1977, p. 38). "Visa obter indicadores. (quantitativos ou não) que permitam a inferência de conhecimentos relativos às condições de produção / recepção (variáveis inferidas) destas mensagens" (BARDIN, 1977, p. 42).

Para Thiollent (1980, p. 35), "em regra geral, as respostas a perguntas livres são processadas por técnicas de análise de conteúdo". Michelat (1980) vai na mesma direção, afirmando que a análise de conteúdo é de onde derivam as técnicas para a maioria das análises de entrevistas não diretivas ${ }^{3}$. Seja textos transcritos de entrevistas com perguntas livres, transcrições de entrevistas semiestruturadas ou textos de documentos, materiais de divulgação ou publicitários, em qualquer destes casos a análise de conteúdo é um ótimo instrumento para uma interpretação metódica das informações, salvaguardados os cuidados aqui apresentados.

Bardin (1977, p. 40) cita Henry \& Moscovici para defender que não é apenas o texto em si que está em questão, mas as condições de produção destes. Neste sentido, afirma que "qualquer análise de conteúdo visa à determinação mais ou menos parcial do que chamaremos as condições de produção dos textos. [...] O conjunto das condições de produção, constitui o campo das determinações dos textos". Isso para dizer que um texto é
3 Por mais que esse autor faça algumas críticas à forma dominante de uso dessa técnica de análise, dentre as quais, a que considero mais relevante, apresentei anteriormente. 
o resultado de um processo comunicativo, que é condicionado por quem emite, quem recebe, e o contexto em que é expressa determinada comunicação. Então, mais que o conteúdo de um texto está em jogo o conjunto do ambiente que condiciona a expressão desse conteúdo. Novamente recorro a Bardin (1977, p.46) para enfatizar que o que está em jogo, como objetivo central da análise de conteúdo, "é a evidenciação de indicadores que permitam inferir sobre outra realidade que não a da mensagem”. Tal análise, portanto, procura conhecer aquilo que está por trás das palavras sobre as quais se debruça. A análise de conteúdo "é a busca de outras realidades através das mensagens" (BARDIN, 1977, p. 44).

Se o analista publica discursos, o que "implica certa intenção de influenciar o interlocutor” (BOURDIEU, 1999, p. 711), mesmo na condição de quem quer buscar/indicar uma verdade, supostamente universal, o que não dizer dos textos publicitários, políticos, documentos de empresas, ou mesmo o caso de uma entrevista, que carrega não só o discurso de seu emissor, mas também o contexto em que ele está inserido e o resultado de sua relação com o entrevistador.

Segundo Bardin (1977), a análise de conteúdo é realizada com base em três procedimentos que devem ser realizados em ordem sequencial:

a) Descrição: enumeração das características do texto

b) Inferência: "Operação lógica (ou deduções lógicas), pela qual se admite uma proposição em virtude de sua ligação com outras proposições, já aceitas como verdadeiras. Inferir: extrair uma conseqüência” (BARDIN, 1977, p. 39).

c) Interpretação: significação concedida às características do texto descritas anteriormente.

Esta ordenação sequencial apresentada por Bardin traz à tona outro problema dos procedimentos normalmente adotados pela análise de conteúdo, para o qual novamente Michelat (1980, p. 210) apresenta uma argumentação: na análise de conteúdo, “a interpretação só pode ser considerada quando a análise do conteúdo manifesto está concluída”. Enquanto na análise das entrevistas não diretivas "a interpretação se faz primeiro, concomitantemente à análise de cada uma das entrevistas, estando sempre à escuta do que o indivíduo singular que fala quer dizer”. Neste sentido, para ele uma entrevista pode já dar uma proposta de esquema interpretativo, não precisando esperar 
o conjunto da descrição, seja de cada entrevista em particular, seja do conjunto delas. Propõe uma análise de entrevistas não estruturadas alternando as leituras verticais e horizontais entre elas. Ou seja, lendo cada entrevista em seu conjunto para analisar seu todo compreensivo e também lendo várias entrevistas concomitantemente, identificando temas comuns que perpassam mais que uma delas. Ele afirma: “um elemento do 'raciocínio' pode faltar em uma entrevista e ser encontrado em outra. Um elemento que só apareceu em uma entrevista pode, assim, levar a um novo 'questionamento' do conjunto do material” (MICHELAT, 1980, p. 206). Desta forma, o esquema que vai sendo estruturado "se transforma, simplificando-se e enriquecendo-se ao mesmo tempo. As 'incoerências' devidas à mistura de muitos níveis desaparecem quando se pode reconstituir o 'raciocínio' que leva às emergências manifestas" (MICHELAT, 1980, p. 209)

Certamente, conforme já apresentado anteriormente, no momento da interpretação a significação é dada pelo novo processador do conteúdo do texto, o analista. A leitura do analista deve ir além de uma leitura superficial, mas "antes realçar um sentido que se encontra em segundo plano"(BARDIN, 1977, p. 41)

Observando os três procedimentos para análise de conteúdo, apresentados com base em Bardin, gostaria de considerar, quanto às inferências, que elas podem responder basicamente a dois tipos de problemas: o que conduziu a um determinado enunciado (causas ou antecedentes da mensagem); e quais consequências que um determinado enunciado vai provavelmente provocar (efeitos da mensagem). Neste sentido, pode-se inferir a partir da procedência ou do destino da mensagem. Observe-se que, apesar da crítica de Michelat apresentada acima ser pertinente e sua proposição de análise ser considerada adequada, isso não tira da análise de conteúdo a necessidade de produzir inferências. $\mathrm{O}$ que pode ficar como mais relevante deste debate crítico é a necessidade de não se seguir necessariamente a ordem sequencial apresentada por Bardin.

Conforme mencionado anteriormente, a análise de conteúdo pode ser de dois tipos: a análise de discurso e a análise de documentos. A análise de conteúdo do discurso tem a especificidade de trabalhar com unidades linguísticas superiores à frase: os enunciados. A análise de documentos busca dar ao texto uma forma mais conveniente para o interesse científico e representar de outro modo a informação contida no documento. Em ambos os casos ocorrem procedimentos de transformação, 
4 Este ponto de vista é partilhado por Michelat (1980), que demonstra a importância de registrar outras percepções do processo de entrevista, indicando até a possibilidade de grava-las em vídeo. os quais são mais evidentes na análise documental, já que esta trabalha com produtos bem definidos (os documentos) para fazer a tradução.

A análise de enunciação é, portanto, uma forma de análise de conteúdo. Ela "apóia-se (sic) numa concepção de comunicação como processo e não como dado e funciona desviando-se das estruturas e dos elementos formais", o que é o caso da análise documental (BARDIN, 1977, p. 169). Ela cabe bem a várias situações, mesmo a textos pré-elaborados, mas adapta-se especialmente bem à entrevista não diretiva. $\mathrm{O}$ objetivo e a ambição da análise de enunciação é apreender ao mesmo tempo diversos níveis imbricados (ao contrário da análise de conteúdo estrita com ênfase na análise documental - que se apoia essencialmente no registro semântico elementar).

Michelat (1980, p.208) propõe algo que se aproxima da análise de enunciação, diferentemente de uma proposta mais esquemática da análise de conteúdo. Reforço que sua proposta indica que o roteiro de análise deve ir se formando ao longo das transcrições das entrevistas, na medida em que novas e mais informações se explicitam. Vai se estruturando um esquema que vai sendo modificado à medida que se segue analisando novas entrevistas. "Em outras palavras, não existe um roteiro de análise a priori”. Ressalve-se que sua proposta de análise é dirigida à análise das entrevistas não diretivas.

Para Bardin (1977, p. 170), "se o discurso for perspectivado como um processo de elaboração onde se confrontam as motivações, desejos e investimentos do sujeito com as imposições do código de linguagem e com as condições de produção, então o desvio pela enunciação é a melhor via para se alcançar o que se procura”. A autora apresenta três tipos de análise pela enunciação: sintática e paralinguística; lógica; e dos elementos formais atípicos: neste caso os silêncios, omissões, dentre outros. Aqui se evidencia seu ponto de vista, portanto, que não é só o enunciado em si que é interpretado na análise de enunciação, mas também o não dito ${ }^{4}$.

Neste contexto a autora indica que a transcrição, para fins de análise de enunciação, deve conservar o máximo de informações linguísticas ou de outras ordens, como perturbações da palavra e aspectos emocionais (BARDIN, 1977, p. 174). Apresenta aí, inclusive, a noção de lapso, que pode ocorrer no momento da resposta a uma entrevista não diretiva e é considerado como 
"uma erupção irracional num contexto racionalizado, que quebra bruscamente a defesa, transgride a norma" (BARDIN, 1997, p. 181). Mas além dos lapsos, falando das figuras de retórica, considera os "Álibis, lugares comuns, jogos de palavras, figuras de retórica, que não são apenas cometidos por descuido por um locutor espontâneo. Os discursos persuasivos (políticos e publicitários) de massa fazem um uso refinado, consciente ou não, destes processos" (BARDIN, 1997, p. 183).

\section{A guisa de conclusão}

As entrevistas, através de questionários semiestruturados e de forma não diretiva, são compreendidas aqui, portanto, como procedimentos metodológicos que podem produzir ótimos resultados na realização da pesquisa social, mesmo que consideradas as diferentes restrições de cada caso, apresentadas ao longo deste artigo. Quando a pesquisa social que se pretende trabalhar está no campo da sociologia política, área do interesse do autor deste ensaio, acredita-se que tais procedimentos são certamente bastante acertados. Apenas entrevista, no entanto, não dá cabo do conjunto que perpassa a ação e a trajetória de líderes sociais, mediadores, políticos de carreira, dentre outros atores sociais relevantes.

Assim, além das entrevistas, a análise do discurso político, dos dados e informações documentais das diferentes institucionalidades locais e das diferentes organizações que as compõem, são procedimentos necessários. Neste contexto, a análise de conteúdo e dentro dela, a análise de enunciação, análise de discurso, bem como o estudo minucioso de cada entrevista operada e do conjunto delas, são procedimentos necessários para a qualidade dos resultados desejados. Isto sem perder de vista que não se está falando apenas em análise dos enunciados em si, mas buscando analisar o contexto que cerca cada enunciado. $\mathrm{O}$ cientista reapresenta textos e contextos reconstruídos comunicativamente, a partir de outros universos cognitivos. Ele reconstrói textos e contextos em sua elaboração literária, a qual ele apresenta como apropriada, e científica. Como neste processo ocorre uma transformação dos conteúdos, revela-se necessário assumir e explicitar a partir de qual base epistemológica fala o cientista. 


\title{
Referências
}

BARDIN, Laurence. Análise de conteúdo. Lisboa: 1977 (Ed. Francesa). Edições 70 .

BAUER, Martin W.; GASKELL, George (ed.). Pesquisa qualitativa com texto, imagem e som: um manual prático. Petrópolis: Vozes, 2003.

BOURDIEU, Pierre. A economia das trocas lingüísticas: o que falar quer dizer. 2a ed. São Paulo: Edusp, 1998.

BOURDIEU, Pierre. A miséria do mundo. Petrópolis: Vozes, 1999.

GHIGLIONE, Rodolphe; MATALON, Benjamin. O inquérito: teoria e prática. 3ª ed. Oeiras: Celta Ed., 1997.

HABERMAS, Jürgen. Consciência moral e agir comunicativo. Rio de Janeiro: Tempo Brasileiro, 1989.

MICHELAT, Guy. Sobre a utilização da entrevista não-diretiva em sociologia. In: THIOLLENT, Michel. Crítica metodológica, investigação social e enquete operária. São Paulo: Polis, 1980.

THIOLLENT, Michel. Crítica metodológica, investigação social e enquete operária. São Paulo: Polis, 1980.

\section{SCIENTIFIC METHOD IN SOCIAL SCIENCES: FROM DOCUMENTS, SURVEYS AND INTERVIEWS TO THE ANALYSIS OF STATEMENTS}

\begin{abstract}
The article proposes a set of reflections to deal with method in social sciences. The interviews and content analysis constitute the major methodological tools analyzed. It also suggests guidelines considered necessary to the methodological practice in social sciences, aiming to escape from the traps and tricks of wordplay. Since all processes of reading, transcription and analysis of texts involve communication among different cognitive universes, a content transformation occurs within them. It concludes by the need of the scientist to assume and explicit that he or she re-presents texts and contexts submitted to the literary construction defined by him/her as appropriate.
\end{abstract}

Keywords: Social Sciences. Methodological tools. Interviews. Content Analysis.

REVISTA GRIFOS - N. 32/33 - 2012 